\title{
The Relationship between Level of Students' Participation in Games Programs and Academic Achievement in Rongo Sub-County Secondary Schools
}

Derrick Okinyi Deya: Rongo University, Kenya.

\begin{abstract}
The purpose of the study was to establish the relationship between the level of students' participation in games programs and academic achievement in secondary schools in Rongo Sub-County. The study adopted descriptive survey and correlation designs. The sample size was as follows: 350 form four students participating in games, 175 boys and 175 girls which were 33\% of the target population. Pearson Product moment Correlation was used to investigate relationship between students' participation level and academic achievement. The Bonferroni Post Hoc Multiple Comparison Test is an analysis method that was used to establish multiple levels of participation to prove relationship with academic achievement. The study found out that there is a minimal positive relationship between students' level of participation in games programs and academic achievement in secondary schools in Rongo Sub County. ( $t$ (350) $r=0.260, p=0.453$ ).
\end{abstract}

Key words: Games, Participating in games, Level of participation, Academic achievement.

\section{Introduction}

Games programs are always carried out at different levels. Alexandria (2004) lists the several levels that games programs can be carried out in a school setting namely class level, inter-dorms level, school level, zone, region and national levels. Each participant in games programs both in team and individual sports strive to reach the highest level of participating in games. Today, it is common to hear faculty discussions degrading the value of games programs from the college level down to junior high school level in the United States of America. According to Griffith (2004) many believe that games programs represent the worst aspects of academia. Yet the tradition of scholastic team sports has survived. This survivorship suggests a symbiosis between games programs and formal curriculum very different from the adversarial relation common in faculty discussions. Griffith (2004) proceeds that it would be odd within a cultural context characterized by competitiveness, to imagine an educational system that denies the relevance of sporting competitions which is highly manifested by the games programs offered in school.

Since Rongo Sub-County secondary schools have been performing dismally academically and have also not been reaching the higher levels of participation in games programs, Rongo Sub-County Sports Office (2009), thus this study sought to find if there exists a relationship between the level of participation in games programs and academic achievement in Rongo Sub-County secondary schools. The study went further by testing the correlation between each level of participation in games programs and academic achievement.

Numerous studies have been conducted concerning the relationship between participation in games and academic achievement. Broh (2002) found that games programs are associated with an improved grade point 
average. Guest and Schneider (2003) also concluded that games programs do in fact, influence academic performance. Both these studies were theoretical in nature hence the need for an empirical study. Anyango (2012) conducted a study on the influence of games programs on academic achievement of public primary school pupils in Kisumu municipality, Kisumu County, Kenya. The study found out that the more pupils participated in games programs, the more their academic performance declined; this was indicated by an inverse relationship between involvements in games programs. Based on the above stated studies, there seems to be some contradiction on the relationship between games programs and academic achievement. The crucial relationship needs to be addressed especially in the Rongo Sub County secondary schools to help establish why games programs and academics have dismal performance.

Rongo Sub-County secondary schools have not featured much at the regional and national games competitions in the recent past. Very few schools from Rongo Sub-County make it past the regional level and when they do manage to proceed to the national level, they perform dismally as shown on Table 1.

\begin{tabular}{|c|c|c|c|c|c|c|c|}
\hline Year & Rongo & Awendo & Kehancha & Suba & Mabera & Kegogo & Uriri \\
\hline 2008 & 0 & 1 & 4 & 3 & 4 & 4 & 1 \\
\hline 2009 & 0 & 2 & 3 & 2 & 5 & 4 & 1 \\
\hline 2010 & 0 & 1 & 3 & 2 & 4 & 5 & 2 \\
\hline
\end{tabular}

Most studies (Jacobsen \& Chase, 1989; Lisella \& Serwatka, 2007; Sayllor \& William, 1974; Staffo, 1991). attribute poor performance to several reasons such as poor methods used in the implementation of games programs in secondary schools, less attention given to games programs, less value given to games programs, and challenges faced in implementation of games programs. However, no study examined the contribution of games programs to the academic achievement of learners. According to the sources at the Rongo DEO'S office (District Education Office, 2010) in the past three years (2008-2010), it is only St. Pius Uriri (now in Uriri Sub-county) and Rapogi Boys (now in Awendo Sub-county) that have made it past the regional level and then performed better at the national level. It is therefore worth trying to dig deep and find the main reasons why these secondary schools do not perform as those from the neighboring sub-counties and regions as seen in Table 1.

Ulanda girls high school which today is in Awendo Sub-County, once represented the former larger Migori District at the national ball games competitions in volleyball in the year 2007 but of late have not been performing as expected. The boys' schools have are not fairing any better with only Uriri and Rapogi Boys (now in Uriri Sub- County) that have been to the national level but once there they do not make it beyond the preliminaries.

Munuve (2011) and Wood (2007) advised on the need to assess the contribution of games programs towards students' academic achievement in secondary schools. Furthermore, Rongo Sub-County schools have not been performing well in the national examinations. Schools in the sub-county have been getting a mean grade of C- between the years 2007-2009. Table 2 is a summary of the mean score for the sub-county in the Kenya Certificate of Secondary Education examinations which show a downward trend in the years 20072009.

Table-2. Rongo Sub-County Secondary Schools' Mean Scores in KCSE. Against other sub counties

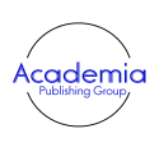

International Journal of Educational Studies Vol. 1, No. 3, pp. 221-228 2018

DOI: $10.53935 / 2641-533 x . v 1 i 3.90$ Funding: This study received no specific financial support. Article History:

Received: 26 July: 2018

Received: 26 July 2018

Revised. 13 September 2018

Published: 24 Decer 2018

Publish. 24 December 2018

() 2018 by the authors; licensee Academic

Publishing Group

\begin{tabular}{llll} 
& $\mathbf{2 0 0 7}$ & $\mathbf{2 0 0 8}$ & $\mathbf{2 0 0 9}$ \\
\hline Rongo & 5.1000 & 5.1471 & 5.3158 \\
Awendo & 6.3712 & 7.3856 & 8.2210 \\
Kehancha & 6.508 & 7.0152 & 7.5031 \\
Suba & 6.2358 & 7.0127 & 7.5213 \\
Mabera & 7.7132 & 6.8401 & 6.5012 \\
Kegogo & 7.3231 & 7.3014 & 7.4256 \\
Uriri & 7.5123 & 8.3451 & 8.7538 \\
\hline Source: Rongo Sub-County Sports Office (2009). & &
\end{tabular}


In the year 2007 the sub-county mean performance in KCSE was 5.3158, which is a mean of C-, while in 2008 and 2009 it was 5.1471 and 5.1000 respectively (Rongo Sub-County Sports Office, 2009). In the subcounty, a study of this nature has never been conducted to reveal the contribution of games to students' academic achievement. There was therefore, need to establish the implementation of games programs and its contribution to students' academic achievement in secondary schools in Rongo Sub-County, Kenya.

Implementation of games programs in secondary schools is not a smooth process. There are several challenges that games teachers do go through in the process of implementing games programs which influences the level in which a school reaches in their participation in games programs. One of the major challenges is budget constraints. When budget constraints result in elimination of educational opportunities for students, administrators should consider the exploration of options that are supported by research. That is the reason it is worth finding out if the level of participation in games programs affect academic achievement. Although some literature was found that indicated a positive relationship between level of participation in games and academics (Foltz, 1992; Howley \& Huang, 1991) a need for more research definitely exists in this area.

Students do participate in games at different levels depending on the country. In Kenya for example, the highest level of participation is the East African regional level where students who win in their respective countries converge. The lowest level that a student can participate in games programs is the school level and this is the level in which most students participate. Most scholars have not written to show whether students who participate at the highest level do perform better in examinations than those who do not reach the higher levels. This study therefore, intends to fill this gap by comparing the performance of students at the different levels of participation in games.

Academic achievement or academic performance is the outcome of education- the extent to which a student, teacher or institution has achieved their educational goals. This is the main objective that all students aim at when they go to school. The big question that comes up is whether they all pass or some do not. According to Magnuson (2007) academic achievement is commonly measured by examinations or continuous assessment but there is no general agreement on how it is best tested or which aspects are most importantprocedural knowledge such as skills or declarative knowledge such as facts (Thomas, 2011) also attests to this fact. Von Stumm (2011) on the other hand says that academic achievement is something you do or achieve at school, college or university-in class, in a laboratory, library or fieldwork. It does not include sport or music. He proceeds to say that an academic achievement, such as graduating $1^{\text {st }}$ class, is sometime a purely quantitative matter, while having the findings of lengthy, comprehensive research published by a recognized journal is also a notable academic achievement.

Why do some students perform better than others in exams? Tomprowski (2008) argues that individual differences in academic achievement have been linked to differences in intelligence and personality. Students with higher mental ability demonstrated by IQ tests and those who are higher in conscientiousness tend to achieve highly in academic settings.

High school life can be stressful, although it is undoubtedly one of the most memorable experiences in one's life. It represents a critical developmental period for both late adolescence and young children (Yakubu, 2012) Social factors such as romantic relationships, organizations and clubs, and sport activities have been found to have effects on students' academic performance. The social factors affect academic performance in times of time demanded and the psychological state they may cause. A student may be influenced to be involved in any of the stated variables. The question is how one strikes a balance between the stressful academic attainment and social activities.

The poor academic performance of most of our students in major external examinations had triggered so many accusations and counter accusations by various groups and individuals. Some had accused parents for their improper caring of their children at home and at school and others point fingers to students for their lackadaisical attitudes forwards their future progress and development while some had launched verbal and physical assault on teachers and school administration and some had blamed the entire education system. The experts in the country responsible for the coordination and administration of education in the country advised people not to put the blame on each other rather help the system to come up with a surmountable and lasting solution to the problem which is seemingly persistent. Kirui (2010) did an analysis of the extent of students' involvement in games activities in secondary schools in Kenya. She discovered that the trend of schools reaching the national level of participation in sports is very predictable in Kenya. You can easily predict 
which schools would reach the nationals and easily predict who will win the championships. The same is applicable to who will reach the zone, and other lower levels of participation in games programs. Munuve (2011) conducted a study on the influence of participation in extra- curricular activities on academic performance of primary schools students in Kitui Central District, Kenya. She realized that extra curricular activities influence students' academic performance with varied effect of the influence depending on the specific extra curricular activity in which the particular students are involved in and the level at which the student reaches in participation. Mustapha (2016) linked attitude of student to the implementation of games programs to the level of participation in games. He discovered that the higher the subjects' participation in competitive games programs, the higher their academic performance, especially when they exhibit positive attitude towards participation in competitive sports.

The literature dealt with here is on the level of participation in games programs and its relationship with academic achievement. It is clear that this relationship has not been clarified by the different studies encountered. No clear relationship between level of participation in games programs and academic achievement has been elucidated. This raises a key question that remains to be answered. Is there a relationship between level of participation in games programs and academic achievement? It is important to address this question hence this study.

It is also important to find out if the level of participation in games programs does affect academic achievement.

\section{Data Analysis}

Data was analyzed using descriptive statistics and Pearson moment correlation using Statistical Package for Social Sciences (SPSS). For descriptive statistics the study examined all the completed questionnaires, and the information contained therein was tabulated in frequency tables and percentages. Pearson Product moment Correlation was used to investigate relationship between students' participation level and academic achievement. The Bonferroni Post Hoc Multiple Comparison Test is an analysis method that was used to establish multiple levels of participation to prove relationship with academic achievement. Jaccard (1984) says that Bonferroni Post Hoc Multiple Comparison Test can be used to determine the significance between group means in an analysis of variance setting. It is very conservative when a large number of means are being compared. The independent variables were measured in terms of a five point Likert scale while the dependent variable was measured in terms of mean scores in RAUJET.

\section{Data Presentation, Analysis and Discussion}

Consequently, the level of participation was measured using a five item scale (1-school, 2-zonal, 3-district (now sub county), 4-provincial (now regional) and 5-national). Students were asked to indicate the level to which they participated in games.

Table-3. Level of Student Participation in Games Programs

\begin{tabular}{lll}
\hline Level of Participation & F & \% \\
\hline School & 392 & 56 \\
Zonal & 54 & 08 \\
District (Sub County) & 162 & 24 \\
Provincial (Regional) & 86 & 12 \\
National & 06 & 07 \\
Total & 700 & 100 \\
\hline Source: Survey Data (2010). & &
\end{tabular}

International Journal of Educational Studies Vol. 1, No. 3, pp. 221-228 2018

DOI: 10.53935/2641-533x.v1i3.90 Funding: This study received no specific financial support. Article History:

Article History:

Received: 26 July 2018
Revised: 13 September 2018

Accepted. 7 December 2018

(O) 2018 by the Dechors; 201

2018 by the authors; licensee Academic

Publishing Group
Results presented in Table 3. indicates that $392(56 \%)$ of the students participating in games programs participated up to the school level, $54(08 \%)$ of the students participated up to the zonal level, $162(24 \%)$ of the students participated in games programs up to the district level, $86(12 \%)$ of the students participated up to the provincial level, while $06(07 \%)$ participated up to the national level.

This finding indicates that majority of students participated in games programs up to the school level, and the number kept on going down as the level increased. 


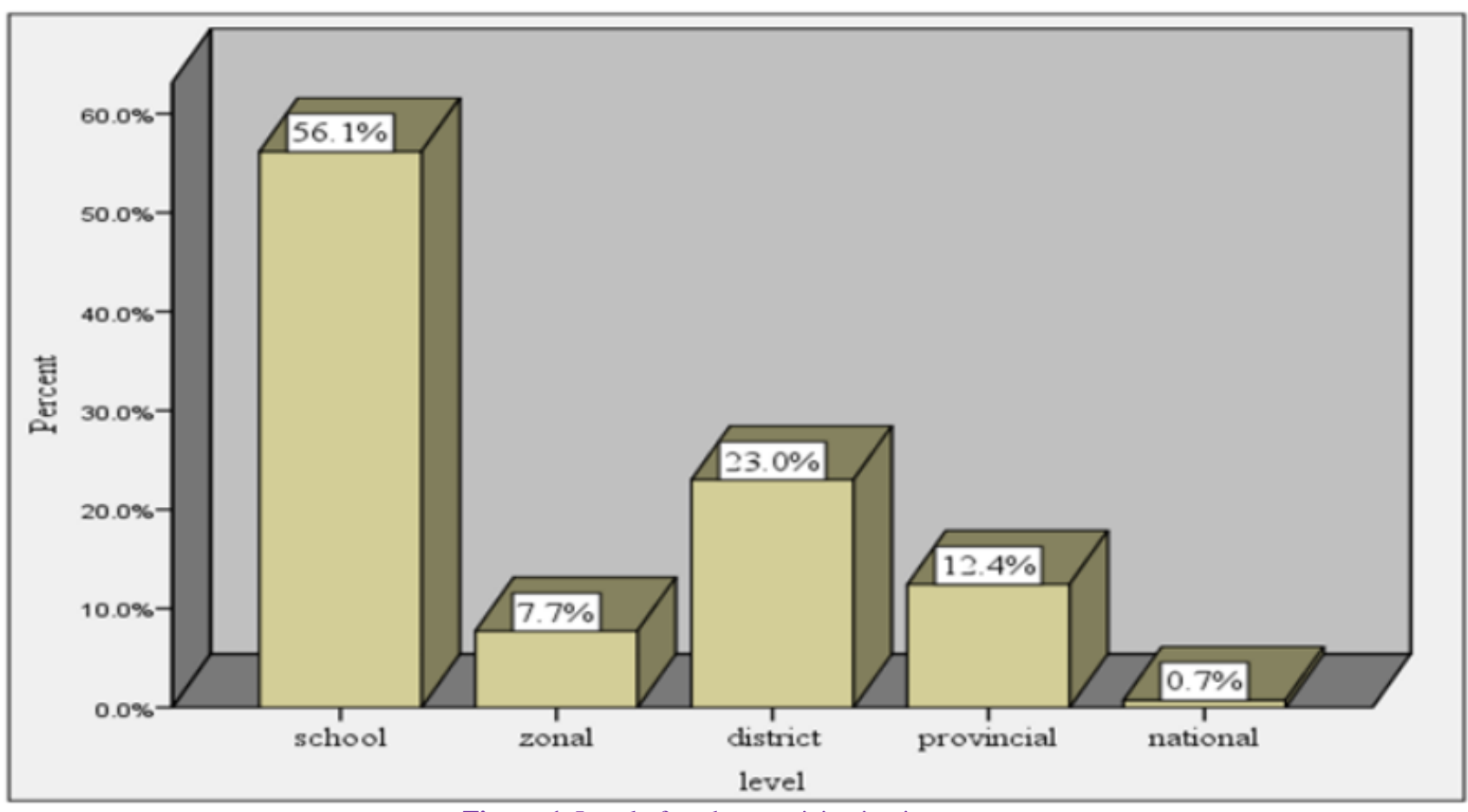

Figure-1. Level of student participation in games.

Results presented in Figure 1 indicate that a majority of the students (56.1\%) participated in games programs only up to the school level. Twenty three percent participated up to the sub-county level (formerly the district level); $12.4 \%$ up to the regional level (formerly Provincial level); $7.7 \%$ up to zonal level; and only $0.7 \%$ participated in games programs up to national level.

These results imply that students in schools in Rongo Sub-County participate in games programs at least up to some level. While most of the students reported to participating in games programs only at school level, others were able to remain competitive up to levels beyond the school level.

\subsection{The Relationship between Levels of Participation in Games Programs and Students' Academic} Achievement

To investigate the relationship between level of participation in games programs and students' academic achievement, level of student participation was first cross tabulated with student's grade in mock exam. Table 4. presents the results of this cross tabulation.

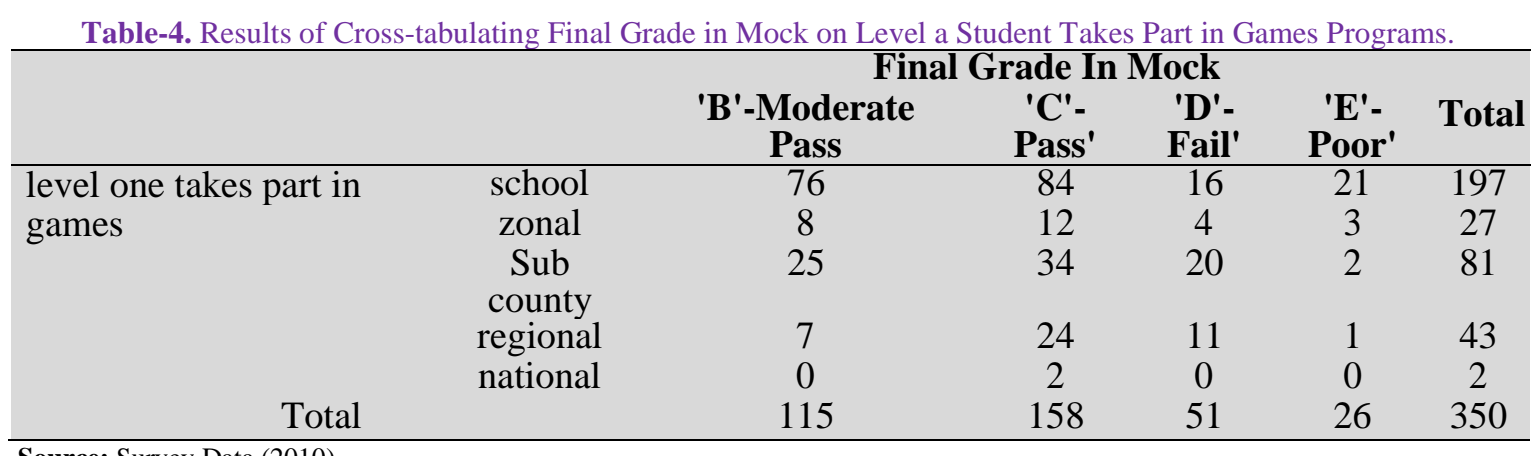

Vol. 1, No. 3, pp. 221-228

2018

DOI: 10.53935/2641-533x.v1i3.90 Funding: This study received no specific financial support.

Article History:

Received: 26 July 2018

Revised: 13 September 2018

Accepled: 7 December 2018

Published: 24 December 201

licensee Academic

blishing Group
Table 4 shows the following. Out of the 197 students whose participation level in games programs was only school, 76 scored a B-moderate pass in mock; 84 scored a C-pass; 16 scored a D-fail, while 21 scored an E-Poor. Out of the 27 students who participated up to zonal level, 8 scored a B; 12 scored a C; 4 scored a D; while only 3 scored an E. out of the 81 students who participated up to sub-county level, 25 scored a grade B, 34 grade C, 20 grade D; while only 2 attained grade E, out of the 43 students who participated up to regional 
level; 7 attained grade B; 24 grade C, 11 grade D; and 1 grade E. All the 2 students whose participation in games programs was up to national level attained grade $\mathrm{C}$.

These results imply that most of the students who attained grades B and C had participated in games programs up to some level. Besides, the significant chi-square statistic tends to suggest that the grade scored in the mock exam dependent on the level of participation in games programs. This in turn leads to improved academic achievement. These findings are consistent with the findings of several other studies (Bowman, 2008; Griffith, 2004; Hollrach, 2008; Kibirige \& Marete, 2008).

The implication of the results on the level of participation in games programs and academic achievement is that the grade scored in the mock examination is dependent on the level of participation in games programs. Students who reach higher levels of games programs are likely to score higher achievement academically.

According to Griffith (2004) games programs play a beneficial role in the development of children into educated and well-rounded students. In supporting these views, Bowman (2008) observed that games provided reluctant students with specific talent related groups of other students with whom to identify and interact with in meaningful goal oriented contexts. The findings that participation in games programs had the potential to lead to improved academic achievement were also echoed by Kibirige and Marete (2008); Njagi (2008) and Mathenge (2008). These authors noted that Dennis Omenda, the top student in Nyanza in the 2007 KCSE had been fully involved in games to the extent of captaining the school's basketball team and yet had gone on to excel in academics. Hollrach (2004) indicates that there were several benefits that learners could reap by participating in games. Such benefits include intellectual and social development which among others focuses students to study habits. These findings further concurred with the findings by Brown (2000) that students who take part in games have a greater advantage over those who do not when it comes to both academic and physical pursuits.

\subsection{Comparing Academic Achievement of Students' Across Different Levels of Participation in Games Programs}

The Bonferroni Post Hoc Multiple comparison test was further used to establish levels of student participation for which there were significant differences in academic achievement. Table 5 presents the results of these comparisons.

Table-5. Results of the Bonferroni Post-Hoc Multiple-Comparisons Test.

\begin{tabular}{ccccc}
\hline $\begin{array}{c}\text { (I) Level one Takes } \\
\text { Part in Games }\end{array}$ & $\begin{array}{c}\text { (J) Level one Takes Part in } \\
\text { Games }\end{array}$ & Mean Difference (I-J) & $\begin{array}{c}\text { Std. } \\
\text { Error }\end{array}$ & Sig. \\
\hline Sub-county & school & $.426^{*}$ & .074 & .000 \\
& zonal & .222 & .124 & .750 \\
& regional & -.082 & .105 & 1.000 \\
& national & -.093 & .359 & 1.000 \\
regional & school & $.508^{*}$ & .094 & .000 \\
& zonal & .303 & .137 & .271 \\
& Sub-county & .082 & .105 & 1.000 \\
& national & -.011 & .364 & 1.000 \\
national & school & .519 & .356 & 1.000 \\
& zonal & .315 & .370 & 1.000 \\
& Sub-county & .093 & .359 & 1.000 \\
& regional & .011 & .364 & 1.000 \\
\hline
\end{tabular}

difference is significant at the 0.05 level.

International Journal of Educational Studies Vol. 1, No. 3, pp. 221-228

Source: Survey Data (2010)

As shown from Table 5, there were significant mean differences in academic performance between students who participated up to sub-county level and those who participated only at school level (mean difference $=0.426, \quad \mathrm{p}<0.01$ ) as well as between those who participated up to regional level and those who participated only at school level (Mean difference $=0.508, \mathrm{p}<0.01$ ). In both cases, the mean difference was positive which implies that students whose participation was up to sub-county and regional levels tended to achieve better grades in the mock exam than those who participated only at school level. 
These results suggest that participating in games programs tends to impact positively on the students' academic achievement according to the level of participation. These findings are consistent with the findings by Brown (2000) which indicated that students who take part in games programs have a greater advantage over those who do not in that they develop individualized plans for improving their grades and performance. In addition, Brown noted that games tended to lift students self esteem. The findings further support the views by Firding and Boyer (2007). The two authors argued that games programs not only motivate learning but also enriches it.

To investigate the relationship between the level of participation in games programs and students achievement, product moment correlation was once again used. The mean score for the variable level of participation in games programs was $(M=0.9386)$ while the mean score of academic achievement was $(M=$ 5.6614) as shown in Table 6.

\begin{tabular}{llll}
\multicolumn{4}{c}{ Table-6. Mean For Level of Participation in Games and Academic Achievement } \\
\hline & Mean & SD & N \\
\hline Level of participation in games & 0.9386 & 1.16233 & 700 \\
Final grade in mock exam & 5.6614 & 0.81716 & 700 \\
\hline
\end{tabular}

To compute the correlation between level of participation in games programs and students' academic achievement, Pearson product moment correlation was used. A measure of the mean of methods used in games programs and the mean test score (academic achievement) for each individual score was correlated. The results on the correlation between level of participation in games programs and students' academic achievement is shown in Table 7.

Table-7. Correlation between Level of Participation in Games Programs and Academic Achievement.

\begin{tabular}{llll}
\hline & & Final Grade in Mock & Gender of Respondent \\
\hline Final grade in mock & Pearson Correlation & 1 & .260 \\
& Sig. (2 tailed) & & .000 \\
& $\mathrm{~N}$ & 700 & 700 \\
Level of participation & Pearson Correlation & .260 & 1 \\
& Sig. (2 tailed) & .000 & 700 \\
& $\mathrm{~N}$ & 700 & \\
\hline$* *$ Correlation significant at the 0.05 level (2 tailed). &
\end{tabular}

Results presented in Table 7 indicates a correlation that was significant at the 5\% level $(\mathrm{r}=0.260)$. This implies a minimal (weak) positive correlation between the students' level of participation in games programs and academic achievement which was measured using the mock exam. The results imply that a learner who reaches a higher level of participation in games program is likely to achieve a higher academic achievement. Since this is a group statistic, it is difficult to conclude anything about individual performance and impossible to attribute causality.

\section{Conclusion}

Research question four sought to find out if there is a relationship between the level of students' participation in games programs and their academic achievement. Using a bar chart, the study established the different levels that the students in schools in Rongo Sub-County participated in games programs. The study found out that there were students whose participation was up to zonal, sub-county, regional and even national level.

The study also used the Bonferroni Post-Hoc Multiple Comparison test to establish the differences in the means between the different levels of participation in games programs. The study found out that there was a significant difference in mean academic achievement of students at different levels of participation in games programs. Using a correlational analysis of the means of the different levels of participation in games programs and the students' academic achievement, the study established that there was a minimal positive relationship between the level of participation in games programs and academic achievement. This means that the higher the level of participation in games programs, the higher the students' academic achievement. 
There is a minimal positive relationship between students' level of participation in games programs and academic achievement in secondary schools in Rongo Sub County. The higher the level of participation in games programs, the higher the academic achievement.

\section{References}

Alexandria, B. F. (2004). Non-formal activities in schools. Retrieved from: www.wikipedia.org.

Anyango, V. (2012). Influence of co-curricular activities on academic achievement on public primary schools in Kisumu county. University of Nairobi, Digital Repository: Kenya. Retrieved from: www.erepository.uonbi.ac.ke.

Bowman, E. (2008). Seven ways to increase at-risk student participation in extra curricular activities. National Forum of Teacher Education Journal, 18(3), 232-245.

Broh, B. A. (2002). Linking extra-curricular programming to academic achievement, Who benefits and why? [Electronic Version]. Sociology of Education, 76(5), 89-105.

Brown, D. M. (2000). Education world 2000. Retrieved from: www.education-world.com.

District Education Office. (2010). Rongo sub-county sports reports. Migori, County Sports.

Firding, E., \& Boyer, J. (2007). Game development impact on. Academic Achievement: Retrieved from: www.nasbe.org.

Foltz, P. (1992). Latent semantic analysis for text-based research. Behavior Research Methods, Instruments and Computers, 28(2), 197-202.

Griffith, D. (2004). More scrutiny of high school athletics needed to ensure academics A priority. Retrieved from: www.nasbe.org.

Guest, A., \& Schneider, B. (2003). Adolescents' extra-curricular participation in context, the mediating effects of schools, communities and identity. Sociology of Education, 76(2), 89-105.

Hollrach, R. (2004). Non formal activities. Iowa State University. Retrieved from: www.chpre.ecu.edu.

Hollrach, R. (2008). Non formal activities. Iowa State University.Retrieved from: www.chpre.ecu.edu.

Howley, C., \& Huang, G. (1991). School completion 2002, drop out rates and other implications for meeting natural goal. Challeston, WV: ERIC.

Jaccard, J. (1984). Pairwise multiple comparison procedure, a review. Psychological Bulletin, 96(3), 589.

Jacobsen, L., \& Chase, C. (1989). Student perception and attitudes towards high school activities Dec 1994-Jan 1995. The High School Journal, 78(3), 234-250.

Kibirige, A., \& Marete, G. (2008). Top girl at home with maths. Daily Nation.

Kirui, J. (2010). An analysis of the extent of students' involvement in sports activities in Secondary schools. Journal of Emerging Trends in Educational Research and Policy, 25(1), 35-52.

Lisella, L., \& Serwatka, T. (2007). Extracurricular activities and educational problems. Retrieved from: www.ribaulthigh.org.

Magnuson, K. (2007). Maternal education and children's academic achievement during middle childhood. Developmental Psychology, 20(3), 1497-1512

Mathenge, M. (2008). Address the plight of those who fail, lobby. Saturday Nation.

Munuve, D. (2011). Influence of participation in extra curricular activities in academic performance in primary school students in Kitui Central District Kenya. Unpublished Thesis. University of Nairobi.

Mustapha, A. (2016). Attitude, sports participation and academic performance of undergraduate student athletes in Saudi Arabia. Journal of Physical Education and Sports, 16(3), 1000-1004.

Njagi, J. (2008). Best student-he depended on well wishers, Daily Nation. 3.

Rongo Sub-County Sports Office. (2009). Report on sports performance. Migori: County Press.

Sayllor, J., \& William, M. (1974). Planning curriculum for schools. New York: Holt.

Staffo, D. (1991). The principal can help keep athletics in proper perception. The High School Journal, 74(4), 132- 140.

Thomas, E. (2011). The ernomous technological challenges facing education. Horizon Report.

Tomprowski, P. (2008). Exercise and children's intelligence, cognition and academic achievement. Educational Psychology, 51(2), $111-131$.

Von Stumm, S. (2011). The hungry mind, intellectual curiosity is the third pillar of academic performance. Perspective on Psychological Science, 20(6), 574-588.

Wood, R. (2007). Active education, physical education, physical activity and academic performance. Retrieved from: http://www.activelivingresearch.org/files/Active-Ed.pdf.

Yakubu, N. A. (2012). The effect of social factors on students' academic performance In Nigerian Tertiary institutions dept of computer science. Federal Polytechnic. Auchi, Nigeria. 